\title{
Labor disputes and illegal strikes in sustainable development of Vietnam's industrial parks
}

\author{
Dung $\mathrm{Vu}^{1, *}$ and Tuan Minh Tran ${ }^{1}$ \\ ${ }^{1}$ Graduate Academy of Social Sciences, 477 Nguyen Trai, Thanh Xuan, Hanoi, 100000, Vietnam
}

\begin{abstract}
A survey of 69 foreign-invested enterprises in six industrial parks in southern Vietnam found that strikes occurred at all enterprises with the participation of the majority of employees. Strikes left negative impacts on production and business activities of enterprises as well as the sustainable development of industrial parks. The fundamental cause of illegal strikes was workers' limited knowledge about strikes, the Labor Code, their rights and interests during strikes, low discipline, and mismatch between personal values and industrial working environment. Employees were also easily provoked when it comes to personal interests; as a result, they can cause chaos when provoked.
\end{abstract}

\section{Introduction}

In recent years, the situation of labor disputes and strikes in Vietnam has become more and more complicated. Thousands of strikes have occurred in the last decade; meaning hundreds of strikes occur each year on average. There were strikes that attracted 42,000 participants, such as strikes in industrial zones of Ho Chi Minh City in 2006; many other strikes had 8,000 and 10,000 people involved. It is worth mentioning that these strikes all occurred in foreign-invested enterprises. This greatly affects the implementation of foreign projects in Vietnam, and the attraction of foreign direct investment in Vietnam (Nguyen Huu Dung, 2010).

Strikes in Vietnam tend to increase in frequency and complexity. Starting from economic disputes, strikes becomea social problem because of the chaos they create in industrial parks (Le Thanh Ha, 2010). Some strikes have led to destruction, such as destroying corporate assets or violence. This is a problem that requires immediate actions. Moreover, while the Vietnamese government has issued legal regulations on labor disputes and strikes, analysis of labor disputes and strikes shows that most strikes do not follow the established order and procedure. This situation hinders the effect of strikes to corporate owners, reducing their effectiveness.

It can be said that labor disputes and strikes in Vietnam in recent years have adversely affected the economic development and social stability in industrial parks, and sustainable development of Vietnam's industrial parks.

\footnotetext{
*Corresponding author: vudungtamly@gmail.com
} 


\section{Labor disputes and strikes}

\subsection{Literature review of studies on labor disputes and strikes}

Labor disputes and strikes are global problems; as a result, they have attracted huge attention from researchers. Franzosi (1989) summarized research on strikes in the last 100 years to find the two most popular perspectives in strike research: economic and organizational/political perspectives. Perry and Wilson (2004) analyzed strikes around the world for 32 years (1960-2002). Jeremy Brecher in his book "Strikes" published in 1997 explained the role of strikes inAmerican labor history. Richard Vigilante (1994) published the book "Strikes: The Daily News war and the future of American workers". Oscar Terry Crosby (1910) wrote a guide book "Strike, when to strike, how to strike: A Book of Suggestion for the Buyers and Sellers of Labour". The book addresses morality, legality, causes and solutions of strikes, the purpose of labor unions, labor capital, wage increase and improved working conditions.Mary E. Baruth-Walsh and Greogory Mark Walsh (1995) described the strike of workers at Windsor Ford Company that took place in 1945. T.A. Kochan (1979) explored the attitude of American workers towards union organization. Immanuel Ness (1998) studied labor union and the betrayal of unemployed workers through an analysis of labor conflict in the 1990s. Another noteworthy study is the study by Ann C. Foster (2004) at the United States Bureau of Labor Statistics. This study found that in 14 major strikes occurred in the United States in 2003, 129,200 workers participated and 4.1 million workdays were lost, a significant increase as compared to the statistics in 2002: 46,000 participants and 660,000 working days lost in 19 major strikes in the US.

In Vietnam, there have been several studies on strikes. Nguyen Duy Thong (2000) studied the strikes by Saigon - Cho Lon - Gia Dinh workers in 1971 to fight against wage tax imposed by the Saigon government. Duong Van Sao and colleagues studied 28 enterprises in which strikes frequently occurred and pointed out that strikes happened most often in export food processing companies. According to a report of the Vietnam General Confederation of Labor, there were 125 strikes nationwide in 2004; and the rate continued in 2005 with 72 strikes in the first 7 months of the year (Vietnam General Confederation of Labor, 2005). Many strikes occurred in a large scale, such as the strike Keyhing Tyos Company (a company with 100\% investmentfrom Hong Kong located in Hoa Khanh Industrial Zone, Da Nang) with more than 10,000 participants, or the strike at Chang Shin Company (a company with 100\% investment from Korean located in Dong Nai) which lasted for 4 days with 8,000 participants(Vietnam General Confederation of Labor, 2005). It is important to note that in the Chang Shin strike, workers were involved in provoking behaviors such inciting, enticing, threatening, fighting and hurting. According to statistics of the Ministry of Labor, Invalids and Social Affairs, from January 1995 to March 24, 2006, there were 1,171 strikes nationwide (98 strikes per year); 541 strikes in 2007 and 103 strikes merely in January 2008 (Institute of Workers and Trade Unions, 2010).

The above studies showed the negative impacts of strikes on corporate business activities as well as national economic development. Studies also pointed to the conflict of interest between business owners and workers as the main cause of strikes. This finding provided a useful explanation to increasing labor disputes and strikes in Vietnam in recent years.

\subsection{Conceptualization of strike and illegal strike}

According to the amended Labor Code passed on November 29, 2006, labor dispute and strike are defined as follows:

"Labor disputes are disputes over interests arising in the labor relationship among the 
employee, the labor collective and the employer" (Article 157, Section I, Chapter XIV).Labor disputes include individual labor disputes between employees and employers and collective labor disputes between labor collectives and employers.

Collective labor dispute over rights is the dispute between the labor collective and the employer arising out of the inconsistent explanation and implementation of the law provisions on labor, the collective labor agreement, the labor regulations and other lawful agreements and regulations (Article 157, Section I, Chapter XIV). Collective labor dispute over interestsis the labor dispute arising when the labor collective requests the establishment of new working conditions compared to the law provisions on labor, the collective labor agreement, labor regulations and other lawful agreements and regulations during the negotiation between the labor collective and the employers (Article 157, Section I, Chapter XIV).

A strike is a temporary, voluntary and organized working stoppage of a labor collective to resolve a collective labor dispute (Article 172, Section IV).

Strikes often take place because workers feel resentful over working conditions, wages and other issues. Being on strike is a basic right of workers. It is the last means of selfprotection and also is a signal indicating abnormal labor relations in enterprises. Strikeis the culmination of collective labor disputes. The most obvious sign of a strike is collective work stoppage. A strikeis the most powerful tool of the labor collective to pressure the employer to satisfy their requirements of wages, working conditions and social security, or to require the employer fulfill their obligations according to labor legislation. A strike is considered illegal when:

- It does not arise from a collective labor dispute.

- It is not carried out by workers working in the same enterprise.

- The collective labor dispute has not been or is being settled by an agency or organization in accordance with the Labor Code.

- Employees' opinions about the strike have not been collected as prescribed in Article 174a or when procedures specified in Clauses 1 and 3 of Article 174b of the Labor Code are violated.

- The organization and leadership of the strike do not comply with the provisions of Article 172a of the amended Labor Code of Vietnam.

- The strike is conducted at enterprises which are not allowed to go on strike on the list prescribed by the Government.

- There has been a decision to postpone or suspend the strike.

In legal strikes, the labor union or the representative of the labor collective has the right to decide on the organization or termination of a strike.

\section{Research Methods}

We surveyed 5,862 people using a questionnaire and interviewed 100 people from 69 foreign-invested enterprises in Vietnam. Participants were recruited using random sampling. All participating companies are companies with investment from Japan, Taiwan, Korea Hong Kong. The enterprises were located in 6 industrial zones: Tan Thuan Industrial Park and Tan Tao Industrial Park in Ho Chi Minh City, Bien Hoa Industrial Park and Ho Nai Industrial Park in Dong Nai province, and Tsunami 2 Industrial Park and Tsunami 1 Industrial Park in Binh Duong province.

This study was conducted from 2015 to 2016. The questionnaire focused on employees' awareness of strikes, its causes and consequences.

The majority of workers surveyed had secondary education (35.9\%) and high school education (48.5\%). However, there was still a noticeable percentage of workers with primary school education qualification (3.2\%). Some hadvocational degrees $(12.4 \%)$. 
Regarding job type, the majority of workers were direct labor(83.8\%); 13.6\% of surveyed participants were indirect workers. Workers were equally divided in term of working duration: $37.5 \%$ had worked for 1 year or less in the current company, $29 \%$ had worked for 1-3 years, $33.4 \%$ had worked for more than 3 years. The percentage of workers aged 24-30 was $44.4 \%$, higher than those aged 23 or under $(31 \%)$ or those over 30 years old $(24.6 \%)$.

\section{Results and Discussion}

Before discussing our findings on the nature, causes and consequences of strikes in foreigninvestment enterprises in Vietnam, we presented statistics on the frequency of labor disputes and strikes in Vietnam collected in our previous research.

\subsection{Frequency of labor disputes and strikes}

According Nguyen Huu Dung (2010) and Vu Dung (2016) from 2001 to 2007, there was a significant trend of increase in frequency of strikes. There were 610 strikes in 2001, an 30\% increase compared to 2000 . In 2002, the number of strikes continued to increase $32 \%$ as compared to the previous year, reaching 805 cases. The fastest increase was from 2007 to 2008. From 1,022 cases in 2017, the number of strikes increased to 1,701 in 2018, marking a $66.44 \%$ increase (Nguyen Huu Dung, 2010).

Of the 2,862 strikes occurring in Vietnam from 1995 to 2010,89 cases were at stateowned enterprises, accounting for $3.1 \%$; 674 cases at private enterprises, accounting for 23.5\%; and 2,099 cases at foreign-invested enterprises, accounting for 73.3\% (Nguyen Huu Dung, 2010). Thus, strikes mainly occurred in foreign-invested enterprises in Vietnam.

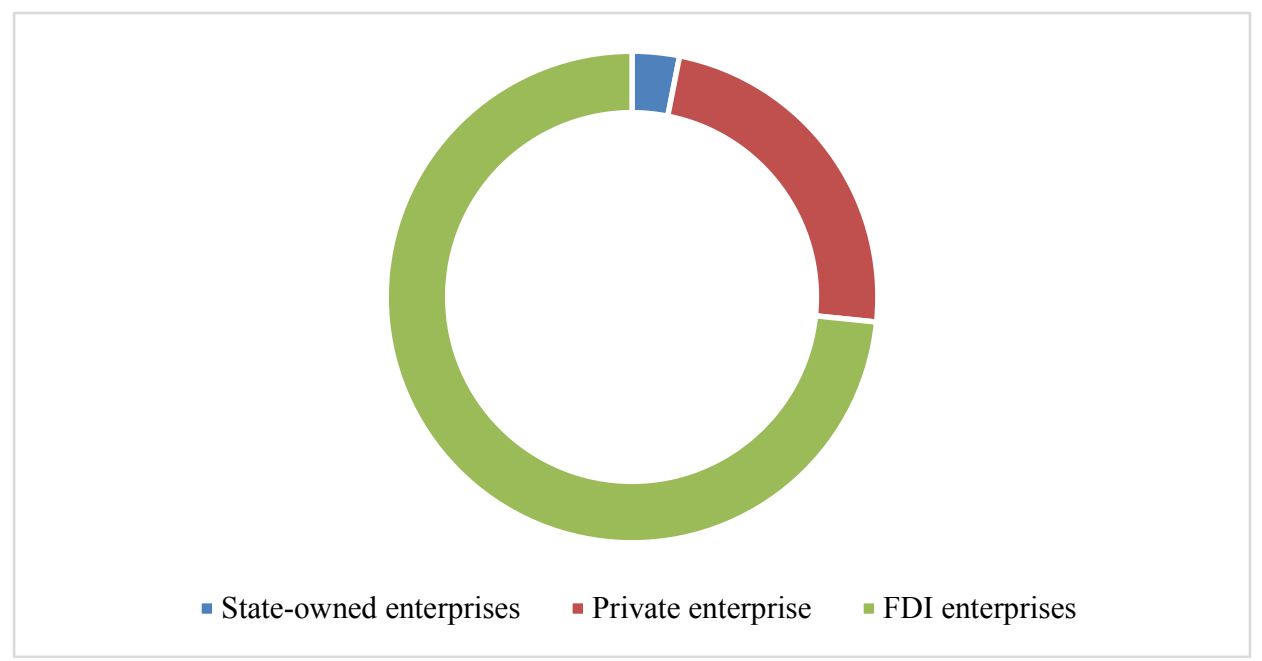

Fig. 1. Number of strikes in Vietnam from 1995 to 2010(source: Nguyen Huu Dung, 2010).

Strikes mainly occurred in Ho Chi Minh City (31.2\%), Binh Duong (23.8\%), and Dong Nai $(21 \%)$. Thus, these three localities accounted for $76 \%$ of the total strikes of Vietnam. Strikes occurred most frequently in industries such as textile industry $(40.28 \%)$ and machinery, food and footwear industries (30.84\%). Of the total 2,099 strikes in foreigninvestment enterprises from 1995 to June 2010, 787 cases occurred in enterprises with investment from Taiwan (37.5\%) and 642 cases in enterprises with investment from South Korea $(30.6 \%)$. Strikes at all other foreign-investment enterprises combined (including 
investment sources from Japan, Hong Kong, Germany, USA, etc.) only accounted for $31.9 \%$ of the total cases (for a review, see Vu Dung, 2016).

In our current survey, $49.2 \%$ of the respondents reported that strikes had occurred in their enterprises. $34.7 \%$ of workers went on strike once; $32.2 \%$ went on strike twice; and $33.2 \%$ went on strike for more than 3 times. With regard to the number of participants in strikes, $54.2 \%$ said that strikes at their enterprises had more than 1,000 participants; $23.6 \%$ reported that 100 to 900 workers participated in strikes in their enterprises; and $22.2 \%$ reported strikes with fewer than 100 participants.

\subsection{Workers' understanding of strikes}

Our survey found that $100 \%$ of strikes in foreign-investment enterprises occurred spontaneously. The organization and procedures of strikes did not follow legal regulations. As a result, none of the strikes went through conciliation at different levels (firm and provinciallevels) or had been handled by the court. Consequently, these strikes fail to influence employers towards better working conditions and warranted labor rights; while they leave negative impacts on business activities of enterprises and the sustainable development of industrial parks (MOLISA, 2008).

Our survey results found that workers' understanding of strikes was the main reason for the failure to follow legal regulations on labor dispute and strikes. Workers' understanding of labor disputes and strikes remained very limited. Table 1 summarized workers' understanding basing on the percentage of correct and incorrect answers they gave.

Table 1. Workers' understanding of labor disputes and strikes.

\begin{tabular}{|l|c|c|}
\hline Issues & Correct answers (\%) & Incorrect answers (\%) \\
\hline Labor disputes & 60.5 & 39.5 \\
\hline The concept of strike & 47.6 & 52.4 \\
\hline Illegal strike & 50.8 & 49.2 \\
\hline $\begin{array}{l}\text { Benefits of workers on } \\
\text { strikes }\end{array}$ & 45.1 & 54.9 \\
\hline The right to go on strike & 58.1 & 41.9 \\
\hline Average & $\mathbf{5 2 . 4}$ & $\mathbf{4 7 . 6}$ \\
\hline
\end{tabular}

In general, a large proportion of the surveyed workers $(47.6 \%)$ did not understand correctly about labor disputes and strikes. $39.5 \%$ of workers understood incorrectly about what a labor dispute is. While no gender difference was found, there were significant differencesin workers' understanding of labor disputes byworking duration and educational background. Workers who had worked in enterprises for less than 1 year had a higher rate of wrong answers than their senior colleagues. Workers with primary education have a higher rate of wrong answers than those with secondary or higher education.

The majority of workers $(52.4 \%)$ misunderstood what a strike was; and slightly less than half of the respondents misunderstood illegal strikes. They considered illegal strikes were strikes organized by labor unions at enterprises. This is contrary to the provisions of Vietnamese law.

It is worth noting that $54.9 \%$ of workersdid not correctly understand the benefits of workers during a strike. For example, may workersbelieved they had "the right to demand salary and bonus as wanted" and "the right to quit job when they feel necessary".Moreover, $41.9 \%$ of workers failed to understand their right to strike correctly. They claimed to have "the right to strike whenever they feel they necessary".

We interviewed leaders in the field to consider labor strikes from a comparative perspective to workers' viewpoint. 
According to Mr. Nguyen Ngoc Phuc, Deputy Minister of Planning and Investment, more than 1,000 strikes over the past 10 years have occurred in the wrong order and procedures prescribed by laws. In some industrial parks, strikes occurred because employers violate the Vietnamese laws or failed to act according Vietnamese culture.

According to Mr. Nguyen Hoa Binh, Vice Chairman of Vietnam General Confederation of Labor, none of the strikes in the last 10 years were organized by grassroots labor union who was supposed to be the legitimate organizers of strikes. He believed that it was time for workers to understand that strikes are the last means when efforts to negotiate and reconcile were unsuccessful.

In accordance with our finding, Nguyen Thi Doan (2008)pointed out that limited capacity of the labor forcewas a cause of strikes. Vietnam's labor force was inadequate in quantity and quality, they failed to meet the requirements of national development. At present, more than $30 \%$ of workers were untrained. More than $50 \%$ of enterprises believed that retraining was necessary for trained workers, especially training in industrial manner, discipline and job attitude.

To sum up, workers did not have adequate knowledge about labor disputes, strikes, and their related right and benefits. This is one of the main reasons leading to the illegal strikes in Vietnam in recent years.

\subsection{Factors influencing workers' understanding of strikes}

Our research results showed workers' understanding of strikes was influenced by 4 factors.

Firstly, a proportion of workers in enterprises has low educational background.In our sample, $39.1 \%$ had primary and secondary education; while those with vocational degree or above accounted for only $10.4 \%$. On the other hand, more than $1 / 3$ ofworkers had been working in the enterprise for less than a year. The lack of formal education and short working durationcontributed to workers' low understanding of necessary working rules, including provisions on labor disputes and strikes. A member of the grassroots labor union in Tan Thuan Industrial Park, Ho Chi Minh City told us: "Workers have low educational background and do not understand the law. Most of them come from farmer families, they are young and don't have industrial manner. Their mental life is unbalanced so they are easily annoyed" (Female union worker, 40 years old, educational level 12/12, working in an enterprise for 3.5 years).

Secondly, there is a sizeable proportion of workers in Vietnam who are untrained or have been trained but fail to meet job requirements. The percentage of trained workers aged 15 and above in 2010 was $14.6 \%$, marking in increase from $12.5 \%$ in 2005 ; yet the average increase rate was only $0.76 \%$ per year. In our survey, workers who finished high school go straight into working for enterprises without going through vocational school. At enterprises, workers receive additional training on occupational knowledge and skills; most of them have not been trained in labor law, including the Labor Code, and workers' right to strike.

Thirdly, most of the workers working in at industrial parks in Vietnam are rural, young people. They bring the culture and psychology of the village into the industrial environment. They have a low sense of discipline, low compliance with the law and highuncertainty in working. They are also easily influenced by social pressure and imitation. When encouraged by others, they are willing to participate in strikes even though they do not fully understand the strikes.

Fourthly, our study found that labor unions at enterprises had not fulfilled their role and responsibility in protecting employees' benefits and organizing employees in labor disputes and strikes. Most labor unions at foreign-invested enterprises in Vietnam have sided with 
business owners for their personal benefits; thus they do not dare to stand up for workers' interests.

\section{Conclusion}

Survey results of 5,862 workers in 69 foreign-invested enterprises in 6 industrial parks in southern Vietnam showed that labor disputes and strikes negatively impacted production activities of enterprises, foreign investment environment and the sustainable development of industrial zones. Most of the strikes were not in compliance with the provisions of Vietnamese law. This reduces the effectiveness of strikes on business owners and has not brought real benefits to workers.

There are many causes of illegal strikes. The main cause is workers' limited understanding of labor disputes, strikes, and their rights and benefits during strikes. Therefore, raising workers' awareness of the Labor Code, including knowledge of strikes and workers' benefits and responsibilities is an important task of labor unions in enterprises in industrial parks today.

\section{References}

1. M. Baruth-Walsh, G. Walsh, Strike: 99 days on the lie: the workers' own story of the 1945 Windsor Ford strike (Penumbra Press, 1995)

2. J. Brecher, Strike. South End Press Classic (1997)

3. O. Crosby, Strike, When to strike, how to strike: A Book of Suggestion for the Buyers and Sellers of Labour (Facsimile Publisher, 1910)

4. The working class in Vietnam - current situation and development trends (Institute of Workers and Trade Unions, Labor Publishing House, 2010)

5. A. Foster, Major work stoppages in 2003. Bureau of Labor Statistics (2004)

6. R. Franzosi, ILR Review 42(3), 348-362 (1989)

7. T. Kochan, Dynamics of dispute resolution in the public sector. Public-sector bargaining. Bureau of National Affairs (1979)

8. Le Thanh Ha, Labor disputes and strikes in Vietnam over the past 10 years (20002010). Research report (2011)

9. Le Thanh Ha, Electronic Communist Review (2008)

10. Luu Van Sung. Workers' strike - situation and solutions in Dong Nai province. Executive report of ministry-funded resesarch project (2007)

11. Invalids and Social Affairs. 111 questions and answers and legal documents on labor disputes and settlement of labor disputes (Ministry of Labor, Labor and Society Publishing House, 2008)

12. I. Ness, Central Labor Councils and the Revival of American Unionism: Organizing for Justice in Our Communities (Taylor \& Francis Group, 1998)

13. Nguyen Duy Thong, The struggle against wage taxes and the combined income of Saigon - Cho Lon - Gia Dinh workers in 1971 (2000)

14. Nguyen Huu Dung, Strikes in Vietnam: Situation and solutions. Research report (2010)

15. Nguyen Thi Doan, Vocational culture (National Political Publishing House, 2008)

16. L. Perry, P. Wilson, Working Paper No. 47 (International Labour Organization, 2004) 
17. Brief report on the situation of workers, employees and union activities, proposals and recommendations (Vietnam General Confederation of Labor, 2005)

18. R. Vigilante, Strike: The Daily News War and the Future of American Labor (Simon \& Schuster, 1994)

19. Vu Dung, Labor disputes and strikes in joint-venture companies and foreign-invested companies in Vietnam. Executive report of government-funded research project (2016) 